\title{
Passive house for a desert climate
}

\author{
I. Marincic, J. M. Ochoa \& M. G. Alpuche \\ University of Sonora, Mexico
}

\begin{abstract}
The first phase of the project presented in this paper consisted of an analysis of the current conditions of the users of social housing units, and has been carried out in different Mexican climatic zones. This diagnosis focused primarily on identifying the users' satisfaction relative to diverse aspects of the house, such as the function of the space, safety, security, environmental conditions, and health conditions, among others. Furthermore, a study has been carried out to find the adaptive thermal comfort range for each climate and the target population.

Another phase of the project was the development of design strategies for social (that is, low-cost) housing units. With the information and results obtained from the low-cost housing developments in Hermosillo, in the State of Sonora in northwest Mexico, a low-cost house model has been constructed for experimental and demonstrative purposes. Passive thermal strategies for hot dry climates have been applied and studied, also taking into account regional (including cultural and regulatory) needs and economic limitations, in order to improve indoor thermal conditions without the use of air conditioning devices.

The test house $-35 \mathrm{~m}^{2}$ of construction area (similar to the existing low-cost houses) - has been constructed on a university campus. Design strategies have been based on the local desert climate: those strategies mainly comprised minimizing heat gains with an adequate orientation, providing solar protection devices, minimizing conduction gains, providing thermal inertia, and allowing nocturnal heat loss. Microclimatic thermal strategies have been applied in the courtyard and surroundings of the building.

Indoor thermal conditions were monitored for more than one year. Air temperature measurements were taken every 10 minutes throughout the study period. Measurements of summer and winter indoor conditions (which are the most representative local seasons) are presented, together with meteorological data, obtained from the university's weather station (LEMA). Indoor temperatures are compared with the adaptive temperature comfort range obtained for the same
\end{abstract}


climate and population, in order to evaluate the effectiveness of the applied strategies.

Keywords: bioclimatic house, adaptive thermal comfort, desert climate.

\section{Introduction}

Tract housing developments have become common in many regions of Mexico. Often, the need for quick and economic construction dictates that dwelling designs are not adapted to local environmental and climate conditions. It is therefore common to observe the same affordable housing models in different climate zones within Mexico, with little or no adjustment for often considerably-varied conditions. Increasing housing demand drives developers to reduce spaces and utilize fewer materials and labor. The quality of housing in general, and energyefficient design in particular, are not a priority, and this results in excessive energy use and high acclimatization costs. Within the framework of a research project titled "Thermal Comfort and Energy Savings of Economical Housing in Mexico: dry and humid hot climate regions", supported by federal funding, several surveys were carried out which measured thermal comfort and energy use in low-cost housing in seven Mexican cities with hot dry and hot humid climates. Field studies yielded a database, which records the impact of housing design solutions on thermal comfort and electricity consumption due to acclimatization in very hot environments, and calculates an adaptive comfort range for the population and climate studied.

In this paper we describe the bioclimatic design of a house model optimized for application in desert climates, which is used for demonstrative and research purposes. The passive thermal design strategies applied in the model are specific to local needs and climate, and also account for economic considerations. This research contributes to the knowledge base which supports actions aimed at increasing the quality of life of low income people, while decreasing differences to reach the comfort conditions and reducing electricity consumption. Considering the large number of dwellings being constructed in cities like Hermosillo, and in Mexico in general, these factors greatly impact the housing sector.

\section{Local climate and comfort studies}

The climate in Hermosillo is hot and dry, characterized by very high levels of solar radiation, clear skies throughout the year, and large temperature oscillations daily and seasonally. The hot season is very prolonged (5-6 months), with daily temperatures between $25-30^{\circ} \mathrm{C}$ and $40-45^{\circ} \mathrm{C}$. The coldest season has a mild climate, with daily minimum temperatures of 4 to $7^{\circ} \mathrm{C}$ and maximum temperatures of 25 to $30^{\circ} \mathrm{C}$. Relative humidity is very low during nearly the entire year. Considering the harsh climate, architectural design criteria and application must be adapted stringently to environmental conditions in order to minimize the negative climate effects on occupants and their energy consumption.

The project consisted of a diagnosis of the current user conditions of the social housing units, in different Mexican climatic zones. This diagnosis focused 
primarily on determining the users' satisfaction relative to diverse aspects of the house, such as the function of the space, safety, security, environmental conditions and health conditions, among others.

The dwellings studied are for low-income families, and their construction is very cost-effective. The dwellings are one-story homes with a constructed area of between $33.5 \mathrm{~m}^{2}$ and $39 \mathrm{~m}^{2}$ (depending on the model), on a lot with an area which varies between $117 \mathrm{~m}^{2}$ and $122 \mathrm{~m}^{2}$. Each has one bedroom, a combined living room-dining room-kitchen area and one bathroom, as well as an outdoor garage. In almost all cases, houses are made of cement hollow blocks with joist slabs and polystyrene vaults. No insulation is present on walls or roofs. Although vaults are made with an insulation material, slabs represent thermal bridges for the roof thermal behaviour. Also, vaults serve as formwork and remain inside the roof, so they are not very efficient as an insulating layer. No solar protection devices are on windows.

Nine low-cost housing developments with these characteristics in Hermosillo, constructed between 2002 and 2005, have been studied. This constitutes nearly the total number of developments handed over to the municipality which have full services and at least one year of occupation. Surveys were applied in order to study different aspects of the dwellings and their occupants. Among other aspects related to the satisfaction of the house, the surveys focused on the thermal comfort sensations of the inhabitants, following the ISO 7730:2005 standard [1].

One survey gathered the physical characteristics of the homes, as well as established a profile of the inhabitants and their perception of the dwelling. The second survey, applied at two different periods of the year, was aimed at recording the thermal sensation of the inhabitants, while simultaneously monitoring the thermal conditions within the home. Subsequently, information was collected on electricity consumption of the surveyed dwellings during the corresponding period.

Occupants' comfort perception during winter and summer was registered in terms of comfort votes between -3 and +3 on the ASHRAE scale [2]. One of the most important comfort results obtained was the adaptive thermal comfort range for the specific climate and population, for the summer and winter conditions (Table 1).

It should be noted that the inhabitants of these homes, according to survey results, have lived in this city for many years and are fully acclimated to the local climate [3].

Taking into account the results obtained from the comfort studies, passive thermal strategies have been proposed which also consider the required construction area, economic restrictions and social considerations.

Table 1: Thermal comfort range limits, obtained from local surveys.

\begin{tabular}{|l|c|c|c|}
\hline Period & $\begin{array}{c}\text { Upper comfort } \\
\text { limit }\left({ }^{\circ} \mathrm{C}\right)\end{array}$ & $\begin{array}{c}\text { T neutral } \\
\left({ }^{\circ} \mathrm{C}\right)\end{array}$ & $\begin{array}{c}\text { Lower comfort } \\
\text { limit }\left({ }^{\circ} \mathrm{C}\right)\end{array}$ \\
\hline Summer (hot) & 29.6 & 32.2 & 34.7 \\
\hline Winter (mild) & 23.5 & 26.9 & 31.3 \\
\hline
\end{tabular}




\section{Case study}

The following are thermal design strategies for low-cost dwellings in one-story tract housing developments. These developments are prevalent in Hermosillo due to the availability of land (despite their design being perhaps not optimally costeffective). Though the design strategies discussed herein focus primarily on thermal aspects, lighting and water-management considerations are also included, since these issues are highly relevant to local conditions. Integration of solar energy systems is also included, to take into consideration the availability of solar radiation in the region.

The architectural design strategies discussed herein seek to favour the habitability of indoor spaces, decrease thermal gains, favour heat loss, and reduce wide temperature oscillations $[4,5]$. In order to achieve these goals, both thermal insulation and high thermal mass are good options. Ventilation is only favourable at nights during intermediate seasons due to the high temperatures, even at night, and due to the proliferation of dust.

Although some of these strategies require relatively low investment and higher design creativity, others such as the integration of renewable energy techniques, would require government subsidies or fiscal incentives [3].

Vernacular architecture examples can be only partially applied in the low-cost dwelling environment, due to economic and construction area limitations. Spanish heritage architecture, which is the remaining traditional architecture (native Indian architecture has not persisted long-term because Indians were nomad), has characteristics such as high ceilings, flat massive roofs, adobe wide walls and clear colour exterior walls. Porches and patios with big trees and fountains are traditional outdoor microclimatic strategies. Because of the very low construction area of the low-cost dwellings, some of these strategies are economically impossible to implement. There are also limitations imposed by local regulations; for example, traditional adobe houses do not qualify for mortgages. Flat roofs, massive roofs and walls, clear colour finishes and the use of shaded patios are strategies that we were able to re-adapt and apply to the house model.

The aforementioned strategies have been applied to the house model, considering the stated needs and limitations. The architectural program and the construction area of the designed model were very similar to those of the low-cost houses constructed in the region.

Because of the necessity for shade most months of the year, the main and back façades are oriented north-south, in order to minimize the east and west solar radiation exposure. Due to local customs and regulations, which demand a service hallway on one of the sides of the dwelling, at least one side elevation needs to be detached. In the case of our model, east and west façades are detached. In spite of this, the neighbouring unit will nonetheless shade these exposed elevations during some periods of the year, presuming model is located in a housing development. Another feature of the house that is related to the strategy described above is the reduction of the surface to volume ratio. That is, the exposed building envelope is reduced to a minimum in relation to the total volume of the unit. 
All openings (doors and windows) are protected by vertical or horizontal solar shading devices, which are designed specifically to meet the shading requirements determined by the latitude of the region. This strategy has been used in north and south elevations, while east and west elevations have no openings. North and south shading devices are interchangeable. Therefore, in the housing developments only one model is proposed for both orientations of the main façade. Additionally, a big mesquite tree, a regional deciduous tree (prosopis velutina), is placed in front of the south façade to provide shade. At Fig. 1, the south façade (main) can be seen with the horizontal and vertical shading devices and the west façade is presented without any openings.

The roof is the greatest heat gain contributor of the building envelope. In our case, the proposed design has a flat roof. The strategy suggested is a roofing system built of a high thermal mass material in the interior layer and a thermal insulation material on the exterior layer, covered by a high-reflectance film. The roofing system selected is a pre-cast aerated concrete panels system [7], which provides thermal mass and low thermal conductivity. It is finished with a layer of white elastomeric insulation as a reflective and waterproofing material, reinforced with a textile membrane. East, west and all exposed walls will follow a similar strategy: the structural parts of the wall will be built with a high thermal mass material, such as compacted earth block. This block has characteristics comparable to adobe, but due to its manufacturing process the specified block is more stable and resistant to weathering than adobe. Another part of the envelope was constructed with aerated concrete blocks [7], with high insulation and medium thermal mass, in order to compare the thermal performance of the envelope made of different materials. Exterior finishes are made of cement and sand (1:5) stucco, painted in a clear colour. No interior finishes are applied. Some of the internal surfaces are white (aerated blocks) and some of them are brown (earth blocks). Clear colours reduce solar radiation absorption outside, and help to reflect natural light inside, reducing the need for artificial lighting and thus lowering energy costs and thermal loads.

The spatial distribution is presented in Figure 3. For the local climate, the least optimal orientation is west, due to of the high temperatures in the afternoon and the low solar altitude. At this side of the plan layout, service spaces have been located, such as the kitchen and the bathroom. In the central part of the roof, a solar "chimney" has been constructed, which allows release of warm air by stratification, controlled, if needed, by opening windows located in the upper part of the duct (Fig. 2(a)).

All exterior areas not subject to traffic have a vegetated ground cover to minimize the infrared reflections, which ground cover is specified to be a species with low water consumption and low maintenance. Gudelia (wedelia trilobata) and lantana (viburnum lantana) species have been used as ground cover meeting these criteria. A locally-adapted deciduous tree (mesquite, prosopis velutina) is planted in close proximity to the south elevation, in order to control the solar radiation on the main façade and on the ground at the entrance of the house. Other low water consumption species, mostly cacti (which have almost no microclimatic impacts) have been used to complete the landscape design. During planning and 
setting selection, it is necessary to consider the full-grown size of the species to prevent possible structural damage to the house and to allow for an adequate growth of the trees.

The proposal also contemplates the incorporation of a solar water heater and a $1-\mathrm{kW}$ network-connected photovoltaic system for energy self-sufficiency (Fig. 2(b)). These aspects are of particular relevance in this region since there is a significant solar resource available that is currently underused.

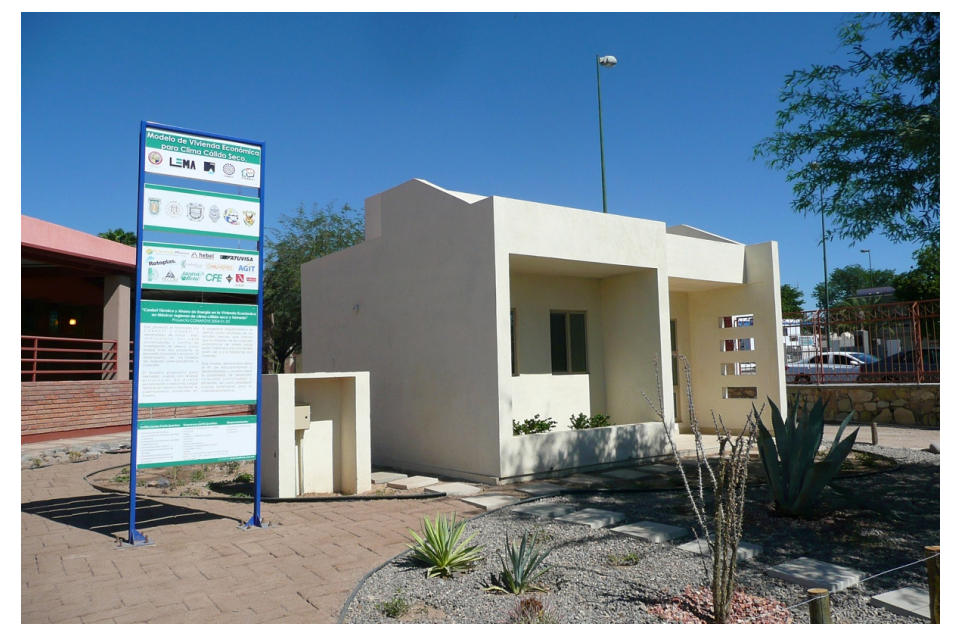

Figure 1: South and west façades' view of the experimental house.

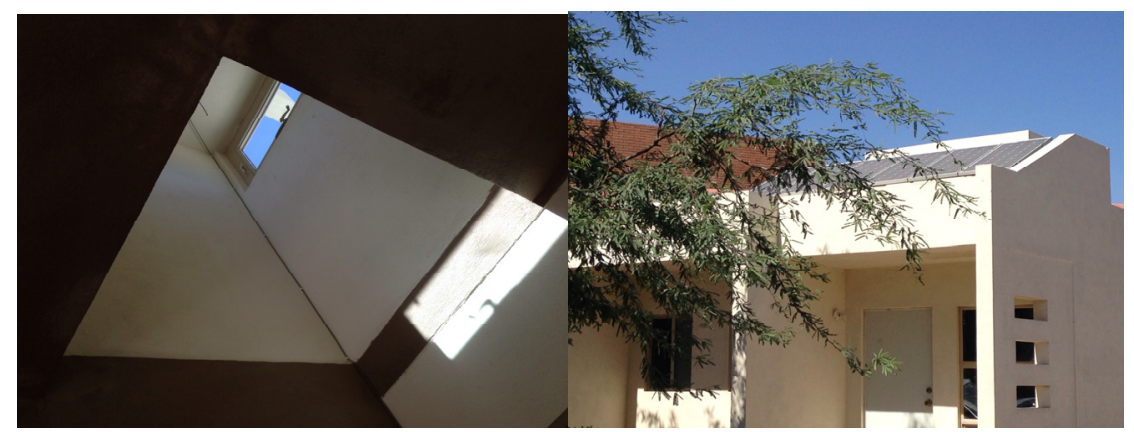

(a)

(b)

Figure 2: (a) Solar "chimney" and (b) photovoltaic panels on the south façade.

To prove that the proposed dwelling is more efficient than current models on the market, the subject of our comfort studies described above, simulations of the energy and thermal performance has been performed on both models, using the software TRNSYS Simulation Studio v. 16, developed by the University of Wisconsin. Details about the simulations have been previously published and can 
be seen in [6]. The project design, constructed in 2012, has been adjusted according to the best simulation results [6].

\section{Monitoring and results}

Indoor thermal conditions have been monitored during more than one year, in order to determine the effectiveness of the strategies. Continuous indoor air temperatures and relative humidity have been taken with HOBO U10 Data Logger every 10 minutes. The sensors have been located in the three main spaces: kitchen, living room and bedroom, according to ISO 7726 [8]. Additionally, four superficial temperature sensors have been installed (Figs. 3 and 4).

The time interval of 10 minutes has been considered to be short enough for the analysis of the building behaviour. It also matches with the time interval of the meteorological station of the Energy, Environmental and Architecture Laboratory (LEMA), which is located about $50 \mathrm{~m}$ away from the test house. This facilitates the data processing. Only one outdoor temperature has been measured, at the porch, but only the data of the mentioned meteorological station has been used as reference exterior data.

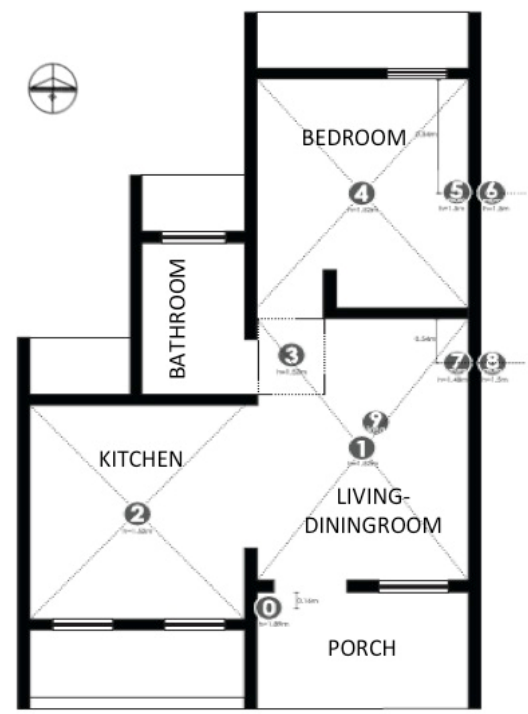

Figure 3: House plan with sensors' location.

Measurements of summer and winter indoor conditions (which are the most representative local seasons) are presented. Measurements taken during an intermediate season, when night ventilation has been used, are also presented. The climate in summer is very hot and in winter is temperate.

In each case, indoor and external temperature are plotted together with the adaptive thermal comfort range obtained for the same climate and population, in order to evaluate the effectiveness of the strategies applied. 


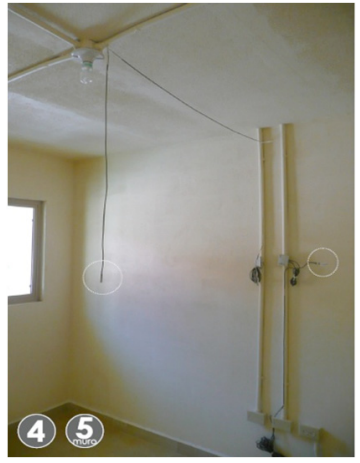

(a)

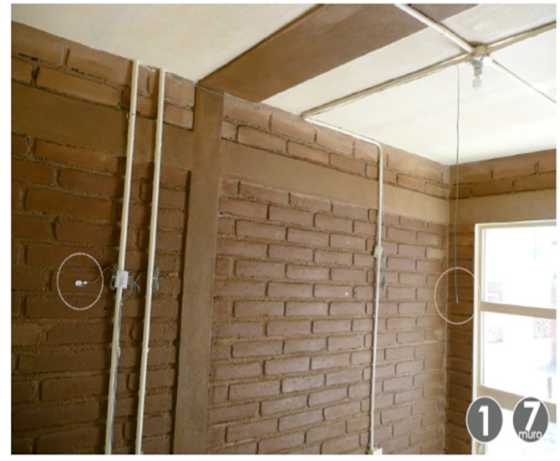

(b)

Figure 4: Indoor air temperature and superficial temperature sensors: (a) in the bedroom and (b) in the living room. The numbers printed in the images correspond to the sensors' location of Figure 3.

The hottest summer months are July and August. One typical week of August is plotted in Fig. 5. Indoor temperatures and outdoor temperature from the meteorological station are presented. The comfort range is also indicated, to compare with the indoor temperatures.

As can be seen at the graph, most of indoor temperatures are lower than the maximal external temperature, and the values are most of the time in-between the comfort range. The comfort range is plotted on the graph in dashed lines.

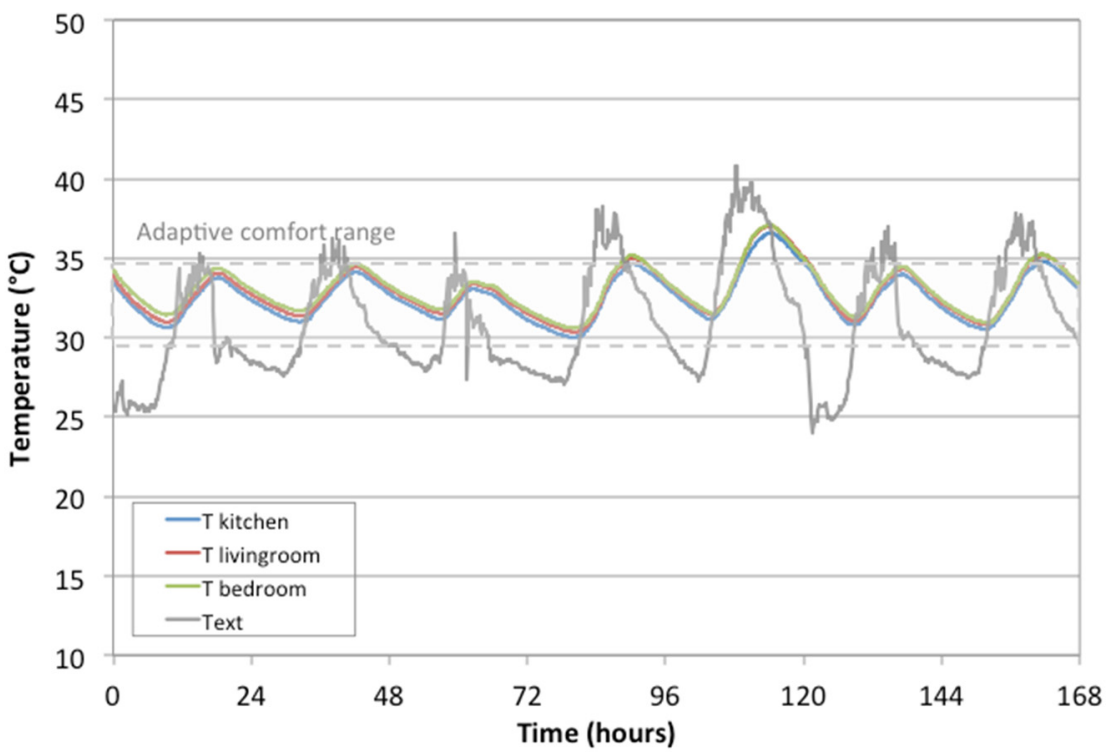

Figure 5: Indoor and external air temperature during a summer week. 


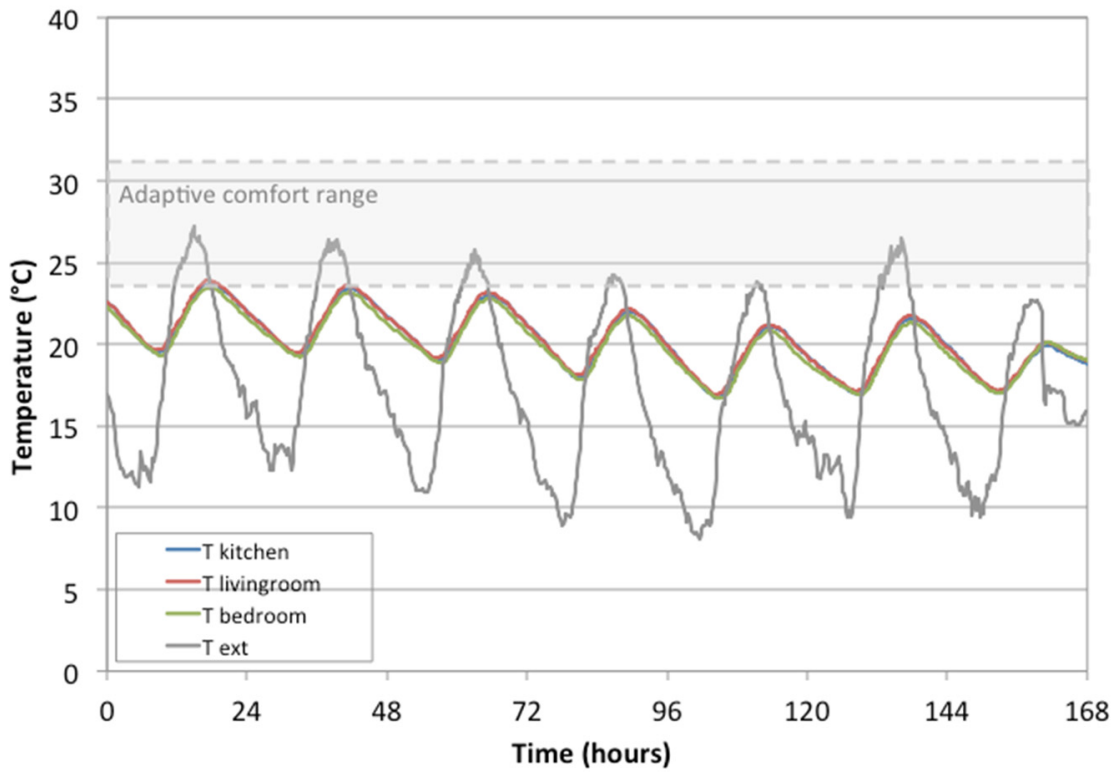

Figure 6: Indoor and external air temperature during a winter week.

Measurements are also presented for one week of the winter season. In general, the coldest winter months are December and January. At Fig. 6 one week of December is presented. The graph of Figure 6 illustrates that indoor temperatures, though not exceptionally low, are lower than the comfort range limits preferred by the users of this type of house (Table 1).

As illustrated, thermal inertia effects (comparing external and internal temperatures) are demonstrated in both periods. This can be seen in the time lag between outdoor and indoor temperatures, and in the significant decrease of the indoor temperature swings. The high thermal inertia responds to the main design strategies applied for this type of climate. Thermal inertia is needed for daily and seasonal periods. The effects of moderate direct solar gains during winter can be seen in higher mean temperature indoors than outdoors (despite absence of internal gains). The strategy was thus demonstrated to be effective.

In the winter case, indoor temperatures are lower than the comfort range. However, some situations must be considered:

- The design strategies were focused on solving the critical situation of the hot season, that spans almost six months of the year, so the house is overprotected from external thermal loads, resulting in slightly lower temperatures in winter that extends for almost three months (December, January and February), with minimum average exterior temperatures of $4-7^{\circ} \mathrm{C}$.

- The monitored winter season 2012-2013 was an unusually cold season. 
Also, internal air temperatures have been monitored in all main indoor spaces, because of their different orientation and also different wall materials. In spite of this, no relevant differences in air temperatures are demonstrated - likely because the house is very small. Indoor air volume is so small that air is quickly mixed by convection and becomes an almost homogenous temperature in the whole volume.

In order to show one of the "active" strategies that the house occupants can apply to the passive systems, we present measurements in an intermediate season, which is the only period that night ventilation can be used. In the summer period, the external night temperatures are too high to reach effective results by night cooling, and the dust pollution also discourages ventilation. Accordingly, ventilation is possible only in some periods of the spring and fall. Night ventilation in the part of the study in which it is possible, is provided by opening all windows in the evening and closing them in the morning.

At Fig. 7 two weeks' monitoring during October is shown. On the graph, the periods of closed windows and night ventilation are indicated. As expected, windows opening increase the indoor temperature swings, but means that indoor mean temperatures can descend. This is a successful strategy for an intermediate season like fall or spring, to maintain lower maximal indoor temperatures.

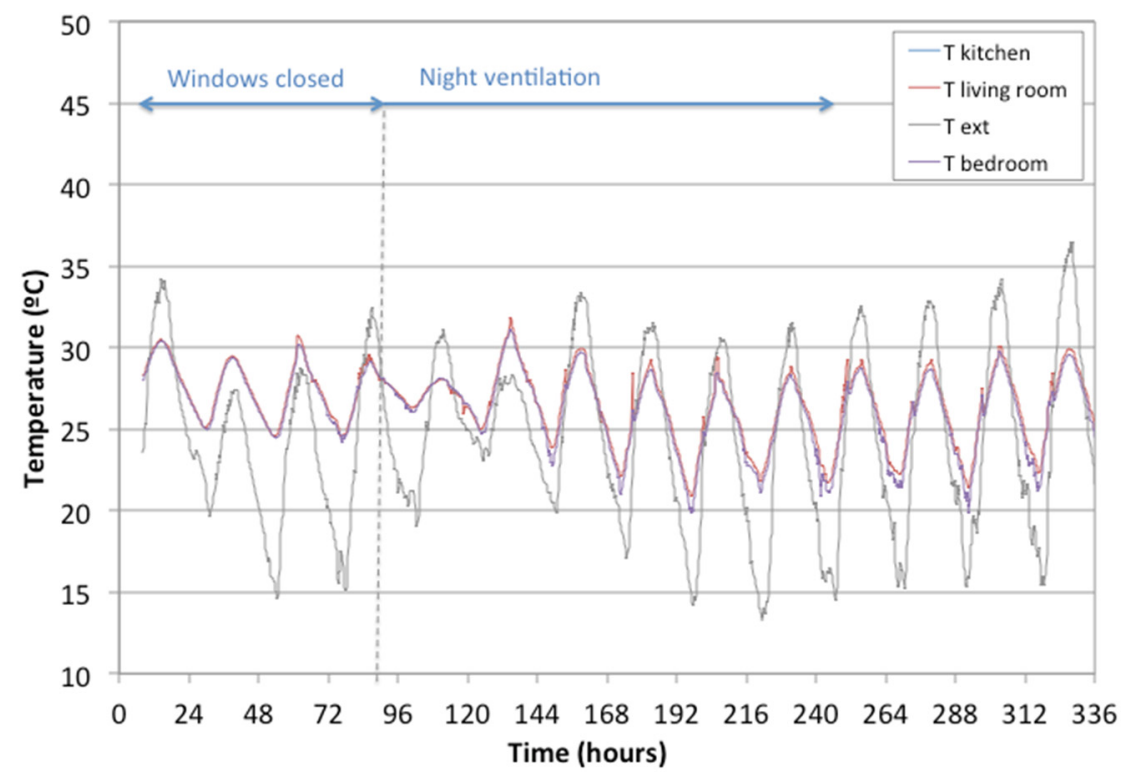

Figure 7: Indoor and external air temperatures during two fall weeks.

The applied thermal strategies are demonstrated to be effective, keeping in mind that it is not possible to reach optimal thermal comfort conditions in the extreme climate in which this study was conducted. However, as is demonstrated in this study, it is possible to improve the indoor thermal conditions and thus to improve the quality of life of inhabitants of these extreme climate conditions. 
Further, in the case of the minority of people who can afford the use of air conditioning devices, it is possible to reduce energy consumptions.

\section{Conclusions}

The goal of this study was to show, using a constructed house model, that if the energy and environmental aspects of housing developments were regulated, economic and environmental impacts could be reduced and the quality of life of low-income homebuyers could be improved.

Even in an extreme climate, like the desert climate of our case study, it is possible to improve the indoor conditions of a low-income typical house, lowering the heat gains in summer and providing moderate heat gains in winter. To describe the house performance, indoor air temperature measurements were compared with temperature comfort limits, obtained from adaptive comfort studies. In the surveys used in these studies, conducted in the city, participate people adapted to the local climate. The adaptive comfort range obtained for the local climate and surveyed population was the reference used to evaluate the house performance.

\section{Acknowledgements}

The National Council for Science and Technology of Mexico (CONACYT), the National Housing Commission (CONAVI) and the University of Sonora have provided the financial support for completion of the Project CONAFOVI 200401-2. We would also like to acknowledge the following sponsors who donated materials and some elements of the house: HEBEL, NUVOTEC, FATUVISA, Contempo Windows \& Design, DALTILE, Instalaciones Félix, Vivero Jardín Bello, PECOM, LADRIECO and ROTOPLAS. Finally we thank graduate students Ileana Gonzalez, Luis Vargas and Esaiy Valdenebro for their collaboration on this project.

\section{References}

[1] International Organization for Standardization. ISO 7730:2005 (E) Ergonomics of the thermal environment - analytical determination and interpretation of thermal comfort using calculation of the PMV and PPD indices and local thermal comfort criteria, 2005.

[2] ASHRAE. ASHRAE Handbook Fundamentals, SI Edition, American Society of Heating, Refrigerating and Air-Conditioning Engineers, 2005.

[3] Marincic, I., Ochoa, J.M., Alpuche, M.G., Thermal strategies for economical dwellings in warm dry climate in Mexico. 27th Conference on Passive and Low Energy Architecture PLEA 2011, Vol. 1, UCL Presses Universitaires de Louvain: Louvain-la-Neuve, Belgium, pp. 571- 576.

[4] Olgyay V. Design with climate. Bioclimatic approach to architectural regionalism. Princeton University Press: 1963. 
[5] Givoni B. Climate considerations in building and urban design. John Wiley \& Sons, Inc.: 1998.

[6] Ochoa, J.M., Marincic, I., Alpuche, M.G., Canseco, S., Borbón, A.C. Bioclimatic and energy efficiency considerations for social housing: a case study in hot dry climate. 9th International Conference on Energy Sustainability ASME 2011, Washington, D.C., USA, pp. 1-10.

[7] Xella Aircrete North America, Inc. Xella Technical Manual. USA, 2010.

[8] International Organization for Standardization (1998). ISO 7726:1998-11-01 Ergonomics of the thermal environment - Instruments for measuring physical quantities, 1998. 